\title{
Investigating The Factors Affecting Successful BSC Implementation In The MAPNA Railway Sector
}

Mohsen Ghaderi, Department of Executive Business, Science and Research Branch, Islamic Azad University, Tehran - Iran Hamidreza Saeednia, Department of Executive Business, Science and Research Branch, Islamic Azad University, Tehran - Iran Hosein Vazifeh Doost, Department of Executive Business, Science and Research Branch, Islamic Azad University, Tehran - Iran

\begin{abstract}
As a performance appraisal system and besides other traditional financial appraisal systems, Balanced Score Card (BSC) evaluates performance of organizations from three other perspectives, including customers, internal business processes, and growth and learning perspectives. As a whole, three main groups of effective factors on successful implementation of BSC are recognized, including Organizational, Staff and Top Management factors. In the verified model, these factors are shown. In the study done in the MAPNA railway sector, a sample of 35 persons was drawn to be used for the distribution of questionnaires. To verify the validity of the questionnaire, the face-validity method was used, and to verify its reliability, we used Cronbach's $\alpha$. To determine the degree of normality of our data, we used the Kolomogorov-Smironov method. Also, Spearman non-parametric correlation tests were used to test the hypotheses. The results verify all three hypotheses which indicate effectiveness of top management, staff and organizational factors in successful implementation of BSC. Top management is the most important factor, followed by organizational and staff. After verification of all three hypotheses, researchers tried to estimate the dependent variable (that is, successful implementation of BSC) using multiple regression analyses and the three main independent variables. This shows the simultaneous impact of the three independent variables on successful implementation of BSC. Based on the results, only staff factor is not statistically significant. It means that, for successful implementation of BSC, if "Top Management" and "Organizational" factors are considered correctly, indices related to staff automatically improve, too.
\end{abstract}

Keywords: Balanced Score Card; Financial Perspective; Customer Perspective; Internal Business Perspective; Learning and Growth Perspective; Top Management Factors; Organizational Factors; Staff Factors

\section{INTRODUCTION}

C nstitutions, enterprises and organizations, based on their missions, visions and goals, perform in national or international levels. They are accountable to stakeholders (including stockholders, customers, etc.). A profitable company that has a high degree of customer satisfaction is always successful, so examining performance results is considered a strategic process (Jasbi, Yaghoobi, et al., p. 102, 2001).

BSC is one of the newest methods to examine performance of organizations, which helps all mangers in all levels to monitor and control their key activities. Robert Kaplan and David Norton are creators of this model in strategic control. They proposed that managers should compile some data from four perspectives, including Financial, Customer, Internal Businesses and Learning perspectives, and then analyze them. As shown in Figure1, these four perspectives provide a framework for BSC (Norton, 2009, p. 253). 


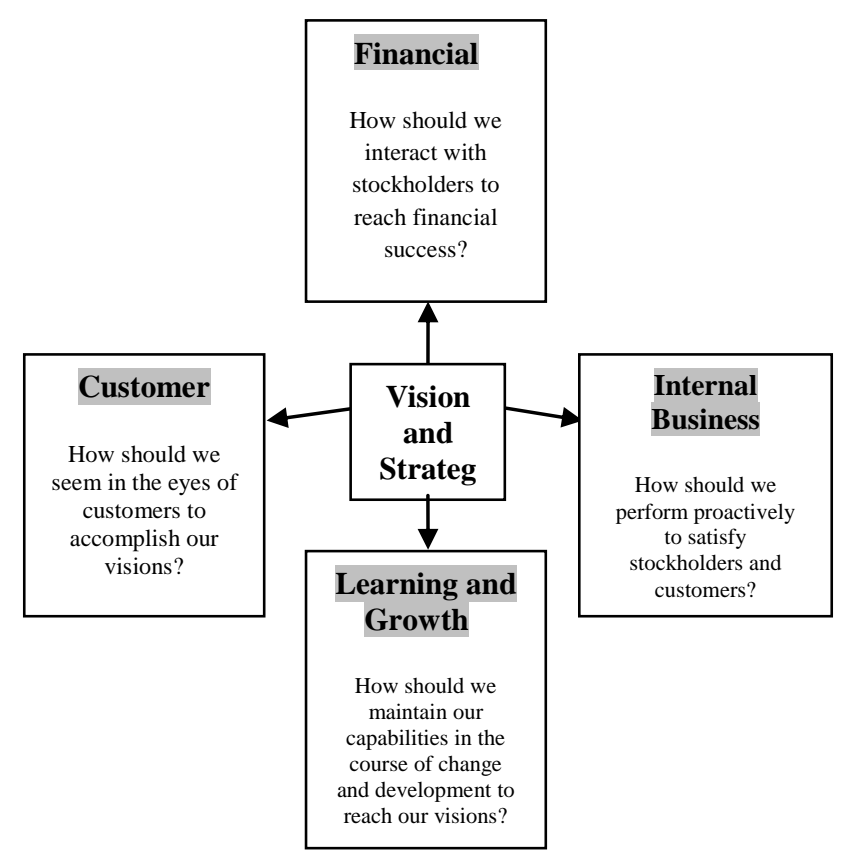

Figure 1: BSC and its Four Appraisal Perspectives (Kaplan and Norton, 1992)

Performance of a comprehensive evaluation system heavily depends on its implementation process in the organization. That means if a performance appraisal system wants to actually evaluate strengths and weaknesses of an organization, the implementation process should be accurately considered. In studies done by Edwin, et al., they concluded that various methods in implementation of BSC lead to different results. This means that, because of unique characteristics of each organization, for a successful implementation of BSC, effective factors in the implementation process should be identified and its conditions should be accurately considered. Researchers tried to study the situation of MAPNA holding company to guarantee successful implementation of BSC. It is relatively easy to identify internal success factors of BSC but difficult to evaluate and monitor external factors. Identification of effective factors in the company can be a suitable model for other companies in MAPNA group or international corporations.

\section{CONCEPTUAL MODEL}

Kaplan and Norton refer to some leading factors in successful implementation of BSC, including staff and top management. In an article issued in 2009 at Harvard University, Kaplan wrote that support and stability of managers during implementation process of BSC are some of the most important top management factors. In addition, he believed that allocation of necessary resources for implementation of BSC is one of the key factors in its correct adoption in organizations. Also, about staff factors, Norton believed that group goal-setting and feedbackbased trainings are some effective staff-related factors in implementation of BSC (Kaplan and Norton, 2009, p. 263).

Moreover, Edwin, et al., in their studies for implementation of BSC in Dutch companies, refer to awareness and consensus of staff for BSC. They believe that increasing awareness of personnel about the BSC implementation process increases its chance of success (Edwin \& Braam, 2004, p. 337).

For organizational factors, Jackie Deem has done a lot of investigations. He believes that recognizing organizational culture and current situations are some of the most important factors in successful implementation of BSC. He adds that for successful implementation of BSC, vision, mission and strategies of organization should be considered to coordinate this appraisal system with long-term goals of the entity (Deem, 2009, p. 118). 
Based on library studies and investigation of viewpoints of experts and managers, three main factors were identified in successful implementation of BSC, including:

$\begin{array}{ll}\text { 1. } & \text { Top management Factors } \\ \text { 2. } & \text { Staff Factors } \\ \text { 3. } & \text { Organizational Factors }\end{array}$

As you see in Figure 2, each of the factors can be divided into some sub-categories

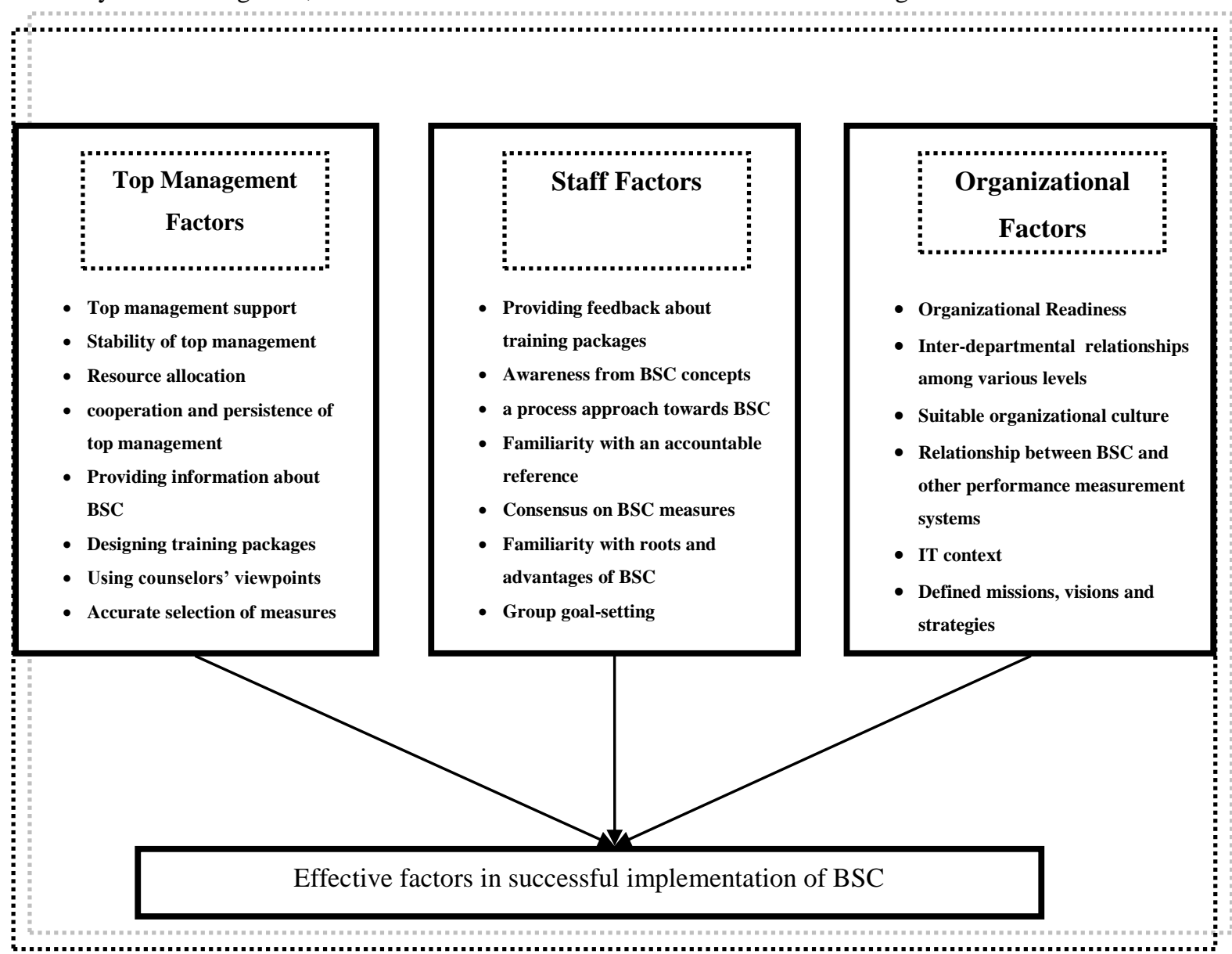

Figure 2: Conceptual Model, Relationship among Effective Factors in Successful Implementation of BSC (Kaplan and Norton, 2009)

\section{Successful Implementation}

Successful implementation of BSC means that all four organizational factors should be accurately and realistically monitored. These include financial, internal business, customer, and growth factors. Then strengths and weakness of each one can be clarified for managers (Kaplan and Norton, 2009, p. 102).

\section{Organizational Factors Hypothesis}

Organizational factors mean those factors that consider organizational aspects and examine the current situation of the organization for cultural factors, its visions, missions and strategies. In fact, situation of an organization would be discussed before implementation of BSC to assess its probable limitations during the 
implementation process (Deem, 2009, p. 87).

$\mathbf{H}_{1}$ : $\quad$ Organizational factors are effective in successful implementation of BSC.

Top Management Factors Hypothesis

In this aspect, top management support is considered in implementation of BSC. Stability of top management in the process and allocation of resources are considered effective factors in successful implementation of BSC (Norton, 2009, p. 275).

$\mathbf{H}_{2:} \quad$ Top Management Factors are effective in successful implementation of BSC.

\section{Staff Factors Hypothesis}

These factors concentrate on awareness of employees from BSC and their consensuses on measures. Training people based on feedback received and setting achievable and cooperatively-defined goals are some of the important factors (Kaplan, 2009, p. 273).

$\mathbf{H}_{3}$ : Staff Factors are effective in successful implementation of BSC.

\section{RESEARCH METHODOLOGY}

From data gathering and research points of view, this study is considered as a survey and descriptive method. It is also applied and cross-sectional research. Statistical population includes managers of MAPNA railway sector. Since volume of the society is limited, a simple systematic random sampling method is used. Because this study tries to identify effective factors on successful implementation of BSC, the sample includes those experts of the company which are familiar with concepts of BSC. To draw a sample, 35 experts of the company were selected and the questionnaires were distributed among them.

\section{GATHERING DATA}

To gather required data, some library researches and similar cases were studied. Then a prototype questionnaire was prepared and corrective viewpoints of professors and experts were considered and distributed among some commentators to find probable erroneous or irrelevant questions. Consequently, the final questionnaire was designed and distributed among the sample group. The questions were based on a five-point Likert scale. Face validity and Cronbach's alpha were used to determine its validity and reliability, respectively. Fifteen questionnaires were distributed among the people as a pre-test, and the answers were tested by SPSS software. The alpha was equal to 0.928 .

\section{ANALYSES AND FINDINGS}

To test normality of the data, a Kolmogorov-Smirnov test was used. Findings of the test for top management showed that the data are not normal. P-value was equal to 0.01 and because it was less than 0.05 , nonparametric methods were used to analyze data. For organizational and staff factors, the related p-values were 0.044 and 0.018, respectively. Also, the relevant value for successful implementation of BSC was 0.035. As KolmogorovSmirnov test results show, none of the data are normal (for values less than 0.05), so non-parametric methods should be used for analyzing data.

\section{HYPOTHESES TESTING}

Because normality assumption of data is rejected, non-parametric methods are used to test the hypothesis. 


\section{Testing the First Hypothesis}

Hypothesis: Organizational factors are effective in successful implementation of BSC.

There is no relationship between "organizational factors" and "successful implementation of BSC". $\mathrm{H}_{0}: \mathrm{p}_{1}=0$

There is a relationship between "organizational factors" and "successful implementation of BSC". $\mathrm{H}_{1}: \mathrm{p}_{1} \neq 0$

In the above hypothesis, $\mathrm{p}_{1}$ denotes coefficient of correlation between "organizational factors" and "successful implementation of BSC". The researchers' hypothesis assumes a relationship between the two factors and is based on the $\mathrm{H}_{0}$ hypothesis. Coefficient of correlation and the related test of the hypothesis are done using the Spearman method as shown in Table 1.

Table 1: Correlation Test for the First Hypothesis

\begin{tabular}{|l|c|c|}
\hline \multicolumn{2}{|c|}{ Spearman non-parametric Correlation Test } & Organizational Factor \\
\hline \multirow{4}{*}{ Successful Implementation of BSC } & $\begin{array}{c}\text { Spearman non-parametric } \\
\text { correlation coefficient }\end{array}$ & 0.502 \\
\cline { 2 - 3 } & probability & 0.02 \\
\cline { 2 - 3 } & number & 35 \\
\hline
\end{tabular}

Based on the calculated Spearman coefficients of correlation and their probability (less than 0.05), the null hypothesis is rejected and the researchers' hypothesis is accepted.

\section{Testing the Second Hypothesis}

Hypothesis: Top Management is effective in successful implementation of BSC.

There is no relationship between "Top Management" and "Successful Implementation of BSC". $\mathrm{H}_{0}: \mathrm{p}_{2}=0$

There is a relationship between "Top Management" and "Successful Implementation of BSC". $\mathrm{H}_{1}: \mathrm{p}_{2} \neq 0$

In the above hypotheses, $\mathrm{p}_{2}$ denotes coefficient of correlation between "Top Management" and "Successful Implementation of BSC". The researchers' hypothesis assumes a relationship between the two factors and is based on the $\mathrm{H}_{0}$ hypothesis. Coefficient of correlation and the related test for the hypothesis is done using the Spearman method as shown in Table 2.

Table 2: Correlation Test for the Second Hypothesis

\begin{tabular}{|l|c|c|}
\hline \multicolumn{2}{|c|}{ Spearman non-parametric Correlation Test } & Top Management Factor \\
\hline \multirow{3}{*}{ Successful Implementation of BSC } & Spearman non-parametric correlation coefficient & 0.516 \\
\cline { 2 - 3 } & probability & 0.01 \\
\cline { 2 - 3 } & number & 35 \\
\hline
\end{tabular}

Based on the calculated Spearman coefficients of correlation and their probability (less than 0.05), the null hypothesis is rejected and the researchers' hypothesis is accepted.

\section{Testing the Third Hypothesis}

Hypothesis: Staff factor is effective in successful implementation of BSC.

There is no relationship between "Staff Factor" and "Successful Implementation of BSC". $\mathrm{H}_{0}: \mathrm{p}_{3}=0$ 
There is a relationship between "Staff Factor" and "Successful Implementation of BSC". $\mathrm{H}_{1}: \mathrm{p}_{3} \neq 0$

In the above hypothesis, $\mathrm{p}_{3}$ denotes coefficient of correlation between "staff Factors" and "successful implementation of BSC". The researchers' hypothesis assumes a relationship between the two factors and is based on the $\mathrm{H}_{0}$ hypothesis. Coefficient of correlation and the related test for the hypothesis is done using the Spearman method as shown in Table 3.

Table 3: Correlation Test for the Third Hypothesis

\begin{tabular}{|l|c|c|}
\hline \multicolumn{2}{|c|}{ Spearman non-parametric Correlation Test } & Staff Factor \\
\hline \multirow{3}{*}{ Successful Implementation of BSC } & Spearman non-parametric correlation coefficient & 0.498 \\
\cline { 2 - 3 } & probability & 0.04 \\
\cline { 2 - 3 } & number & 35 \\
\hline
\end{tabular}

Based on the calculated Spearman coefficients of correlation and their probability (less than 0.05 ), the null hypothesis is rejected and the researchers' hypothesis is accepted.

\section{OTHER FINDINGS}

After verification of all three main hypotheses, the researchers ranked current indices for organizational, top management and staff factors using Spearman coefficients of correlation. For top management, there are two factors - support of top management and preparing training packages - which have a high priority. For staff, their awareness from concepts of BSC and having a process approach toward BSC were identified as two main factors. For the organizational factor, availability of IT infrastructures and coordination of BSC with other performance appraisal systems were considered as two main factors.

\section{CONCLUSION}

The current study recognizes effective factors on successful implementation of BSC in the MAPNA railway sector. The main results of the study show that all three hypotheses were accepted. It means that all top management, staff and organizational factors are effective in successful implementation of BSC. Based on the analyses, top management is the most important factor followed by organizational and staff factors.

After verification of all three hypotheses, the researchers tried to use multi-variable regression analysis and the three main variables to estimate their impact on the dependent variable (that is, successful implementation of BSC). This shows simultaneous impact of the three variables on success of BSC. Based on the analyses of the model, only the "Staff" variable is not statistically significant. In other words, for successful implementation of BSC, if "Top Management" and "Organizational" factors are considered correctly, indices related to "Staff" automatically improve too. So, the final regressed model is as shown in Figure 4.

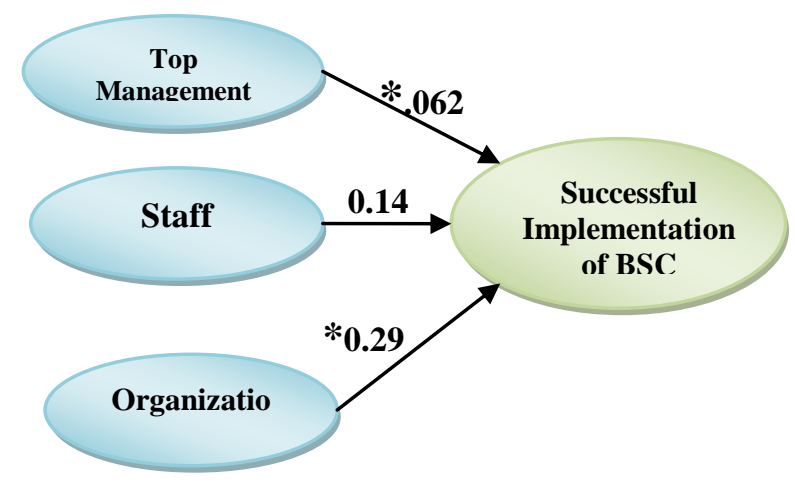

Figure 4: The Final Regressed Model Coefficients Determined with * are Significant with a 5\% Error. Coefficients Determined with * are Significant with a $5 \%$ Error. 


\section{AUTHOR INFORMATION}

Mohsen Ghader is the Executive Master of Business Administration, Islamic Azad University, Tehran science and research branch. Address: toward Hesarak, Ashrafi Esfahani Highway, Tehran, Iran. Corresponding author e-mail: ms_ghaderi@yahoo.com.

Hamidreza Saeednia is an Assistant professor, a member of scientific board of Islamic Azad University, north branch, Tehran, factually of management, south Makarn St., Heravi Sq., Pasdaran St., Tehran, Iran.

Hosein Vazifeh Doost is an Assistant professor, a member of scientific board of Islamic Azad University, Tehran science and research branch. Address: toward Hesarak, Ashrafi Esfahani Highway, Tehran, Iran.

\section{REFERENCES}

1. 2GC Limited (2009), "2GC Balanced Scorecard Usage Survey 2009", "2GC Balanced Scorecard Usage Survey 2009".

2. Amiran, Heidar, "methods of measuring efficiency and effectiveness of quality systems", Keifiat Saz Advisors Company, fall 2001.

3. Articles on performance appraisal systems in governmental organizations, management and productivity center of Tarbiat Modarres University, 2001.

4. Azar, Adel and Momeni, Mansour, "statistics and its application in management", Tehran, SAMT pub., $2004,10^{\text {th }}$ edition, volume1.

5. Bourne, M., and Bourne, P. (2000), Understanding the Balanced Scorecard in a Week, Hodder \& Stoughton, UK, Olve, N.

6. Ch. 1 of "Strategy and Structure: Chapters in the History of the American Enterprise", Alfred D. Chandler Jr., The MIT Press, 1962.

7. Charles Hannabarger, Frederick Buchman, and Peter Economy (2007) Balanced Scorecard Strategy for Dummies Wiley Publishing, Inc. ISBN 978-0-470-13397-2.

8. Cobbold, I. and Lawrie, G. (2002a). "The Development of the Balanced Scorecard as a Strategic Management Tool". Performance Measurement Association 2002.

9. Davig, W., Elbert, N., Brown, S., (2004), "Implementing a Strategic Planning Model for Small Manufacturing Firms: An Adaptation of the Balanced Scorecard". S.A.M. Advanced Management Journal, Vol. 69 Issue 1, p18.

10. e.g. Brignall, S. (2002) "The UnBalanced Scorecard: a Social and Environmental Critique", Proceedings, Third International Conference on Performance Measurement and Management (PMA 2002) Boston, MA, USA July 2002; Butler A. Letza S.R. and Neale B. (1997).

11. Edwin, Roy J., Wetter M. (2008 - English translation, 1st published in Swedish 2007); "Performance Drivers: A practical guide to using the Balanced Scorecard", Wiley, UK.

12. Epstein M.J. and Manzoni J.F. (1997). "The Balanced Scorecard \& Tableau de Bord: A Global Perspective on Translating Strategy into Action"; INSEAD Working Paper, 97/63/AC/SM.

13. GC Performance Management Software Database "2GC Performance Management Software Database".

14. Grönroos C. In search of a new logic for marketing: foundations for contemporary theory. John Wiley and Sons; 2007.

15. Jack deem. (2009). "From Balanced Scorecard to strategic gauges: is measurement worth it", Management Review, Vol.85.

16. Kaplan R.S. and Norton D.P. (2000). The Strategy Focused Organization, HBS Press, USA.

17. Kasper H, van Helsdingen P, Gabbott M. Service marketing management: a strategic perspective. John Wiley; 2006.

18. Keller K, Lehmann DR. Brands and branding research: research findings and future priorities. Mark Sci 2006; 25(6):740-59.

19. Keller K. Conceptualizing, measuring, managing customer-based brand equity. J Mark 1993; 57 (1):1-22.

20. Khaki, Gholamreza (2003), research method: "an approach to writing thesis", first edition, Baztab pub.

21. Maisel, L.S., "Performance measurement: the balanced scorecard approach", Journal of Cost Management, Vol. 6 No. 2, 1992, pp. 47-52. 
22. Malina, M.A., Selto, F.H., (2001), "Communicating and Controlling Strategy: An Empirical Study of the Effectiveness of the Balanced Scorecard”, Journal of Management Accounting Research, Vol. $13, \mathrm{p} 47$.

23. Malina, M.A., Selto, F.H., (2001), "Communicating and Controlling Strategy: An Empirical Study of the Effectiveness of the Balanced Scorecard”, Journal of Management Accounting Research, Vol. 13, p47.

24. Monroe KB. Pricing: making profitable decisions. New York: McGraw Hill; 1990.

25. Mooraj S. Oyon D. and Hostettler D. (1999). "The Balanced Scorecard: A Necessary Good or an Unnecessary Evil?” European Management Journal, Vol.17, No.5.

26. Morgan R, Hunt S. The commitment-trust theory of relationship marketing. J Mark 1994; 58(3): $20-38$.

27. Niven P.R. (2002). Balanced Scorecard Step by Step: Maximizing Performance and Maintaining Results, Wiley, New York, USA.

28. Norreklit H. (2000), "The balance on the balanced scorecard - a critical analysis of some of its assumptions", Management Accounting Research, 11, pp. 65-88.

29. Parmenter, D., (2002), "Implementing a Balanced Scorecard in 16 Weeks", Chartered Accountants Journal, Vol. 81 Issue 3, p19.

30. Payne A, Holt S. A review of the value literature and implications for relationship marketing. Australasian Mark J 1999; 7(1):41-51.

31. Performance Drivers: A practical guide to using the Balanced Scorecard, Nils-Goran Olve, JanRoy, Magnus Wetter. John Wiley \& Sons, 1999.

32. Putting the Balanced Scorecard to Work, Harvard Business Review, Sept. 1993.

33. Rahimi, Ghafoor and Yaghoobi, Eisa (under supervision of Dr. Javad Jasbi), class seminar for master of industrial management, "application of multiple-objective decision theory for Islamic Azad University (science and researches branch)", 2004.

34. $\quad$ Rohm, Howard (2004). "A Balancing Act", Perform Magazine, v. 2 no. 2.

35. Schneiderman A.M. (1999). "Why Balanced Scorecards fail”, Journal of Strategic Performance Measurement, January, Special Edition 6.

36. Sirdeshmukh D, Singh J, Sabol B. Consumer trust, value and loyalty in relational exchanges. J Mark 2002; 66(1):15-37.

37. Sjöstrand, A., (2002), The Balanced Scorecard, Oxford, UK: Capstone Publishing.

38. The Balanced Scorecard - Measures that Drive Performance, Harvard Business Review, Feb. 1992.

39. The Balanced Scorecard: Translating Strategy into Action, Harvard Business School Press, Boston (1996).

40. The Theory of the Growth of the Firm, New York, John Wiley and Sons, 1959, ISBN 9780198289777.

41. Vargo S, Lusch R. Evolving to a new dominant logic for marketing. J Mark 2004; 68(1):1-17.

42. Zeithaml V. Consumer perceptions of price, quality and value: a means-end model and synthesis of evidence. J Mark 1988;52(3):2-22. 